\title{
Addressing Black Inclusivity Within a Canadian Post-secondary Engineering Faculty: a Critical Perspective
}

\author{
Mikhail Burke $^{1}$ (D) Cori Hanson ${ }^{1} \cdot$ Cassandra Abraham $^{1}$
}

Accepted: 31 May 2021 / Published online: 31 July 2021

(C) Ontario Institute for Studies in Education (OISE) 2021

\begin{abstract}
This paper briefly outlines three initiatives that the University of Toronto (U of T) Faculty of Applied Science and Engineering (FASE) has implemented as initial steps as the institution strives to be anti-racist and address Black inclusivity. These initiatives were based within K-12 outreach, racebased data collection and creating opportunities for faculty-wide race-centric dialogue and learning. $U$ of T FASE was compelled to develop and/or enhance such initiatives after an anti-Black racist incident between students was mishandled and criticized by Black student groups. Using critical race theory (CRT) and personal reflection, this paper highlighted several barriers to the implementation and/or success of these initiatives such as time, financial security, perception of institutional policy and/or provincial law, engineering culture and whiteness and/or colour evasiveness. While definitive solutions to these barriers may not be clear, having a designated champion for specific initiatives, addressing discomfort in differentiating race, consistent advocacy to senior administration and the self-empowerment to resource time and effort to such work were identified as key elements to drive initiatives within the context of U of T FASE.
\end{abstract}

Résumé Dans cet article, nous abordons brièvement trois initiatives que la Faculté des sciences appliquées et de génie (FSAG) de l'Université de Toronto (U de T) a mises en place en tant que premières étapes alors que l'établissement s'efforce d'être antiraciste et de relever le défi de l'inclusion des personnes noires. Ces actions étaient concentrées sur des activités de rayonnement de la maternelle à la $12^{\mathrm{e}}$ année, la collecte de données fondées sur la race et la création d'occasions favorisant un dialogue et un apprentissage centrés sur la race dans l'ensemble de la faculté. La FSAG de l'U de T s'est vue contrainte soit de développer, soit d'améliorer ce genre d'initiatives après qu'un incident à caractère raciste anti-noir entre étudiants n'ait pas été traité adéquatement et ait été décrié par des groupes d'étudiants noirs. Par la «Théorie critique de la race» (TCR) et une réflexion personnelle, cet article a fait ressortir plusieurs obstacles nuisant à la réalisation ou au succès de ces initiatives tels que le temps, la sécurité financière, la compréhension des politiques institutionnelles ou des lois provinciales, la culture de

Mikhail Burke

mikhail.burke@mail.utoronto.ca

1 University of Toronto, Toronto, Canada 
l'ingénierie ainsi que la «blanchité» ou bien les faux-fuyants relatifs à la couleur. Alors que des solutions durables à ces barrières ne sont peut-être pas évidentes, les éléments clés relevés pour faire avancer les initiatives dans le contexte de la FSAG de l'U de T incluent le fait d'avoir un chef de file désigné pour mener à bien des actions particulières, la prise en compte des malaises relatifs à la différenciation raciale, une promotion et une défense des droits cohérentes auprès de la haute direction et la capacité de s'engager personnellement pour consacrer le temps et l'effort à ce travail.

Keywords Black inclusivity · Engineering education - Critical race theory · Equity and inclusion · Science outreach

\section{Introduction}

In 2017, the administration at the Faculty of Applied Science and Engineering (FASE) at the University of Toronto ( $\mathrm{U}$ of $\mathrm{T}$ ) became aware of anti-Black racist posts in an online private student group chat. The administration at FASE investigated the situation and attempted to address this incident with the student community; however, this response was criticized by Black students' groups at U of T. In the end, Black students were harmed in this process, being left feeling unacknowledged, unheard, discriminated against and unsafe after this incident, and it became clear that the FASE administration were not equipped to understand or respond to incidents of anti-Black racism within the student community. Subsequent advocacy from Black student groups highlighted a potential gap in racial literacy, awareness and understanding of the Black experience in engineering education from the predominantly white administration responsible for responding to this incident. It could have also suggested a more deeply rooted culture of whiteness and anti-Blackness that was going unrecognized and unnamed at FASE.

Motivated by the resulting student advocacy, the dean of FASE hired an advisor on Black inclusivity initiatives and formed a steering committee to provide recommendations for ways in which Black representation and inclusivity could be improved at all levels of the faculty. Around the same time, the faculty also formed an Engineering Equity, Diversity, and Inclusion Action Group (EEDIAG) to facilitate conversations and programming to address various barriers of inclusion such as anti-Black bias. In the 2.5 years that followed, there have been several initiatives that have been, or in the process of being, integrated within the faculty.

\section{Purpose}

This paper focuses on characterizing the development of three key initiatives meant to address anti-Black racism within the faculty: K-12 outreach programmes for Black youth, race-centric data collection and creating opportunities for faculty-wide race centric dialogue and learning.

The purpose of this paper is to deconstruct, analyse and understand, through the use of critical race theory and reflection, the experiences of the authors and the barriers faced in the development, implementation and/ or adoption of these initiatives. By doing so, the authors seek to both humanize the process of anti-racism work within science, technology, engineering and mathematics (STEM) education and empower others to promote change within their own spheres.

\section{Framing Critical Race Theory}

In this paper, critical race theory (CRT) is used to examine and better understand the barriers experienced by the authors in the implementation of the three key initiatives identified. Founded from the scholarship of Derrick Bell and Alan Freeman, CRT centres racialized experiences and racism in the examination of systemic power within social, cultural and political constructs (Delgado et al., 2017). Broadly, CRT argues that racism and white supremacy exist, are ordinary and are normalized (Bell, 
1992; Delgado, 1995); therefore, more value is given to white racial identity (Harris, 1993). CRT also argues that the socio-political power dynamics of race intersects with the power dynamics of other identities (Crenshaw, 1991) and that these dynamics of racial power are upheld by the laws (Crenshaw et al., 1995). The main themes of CRT identified by Delgado and Stefancic's (1993) work to define and document CRT scholarship are critiques of liberalism; storytelling, counter-storytelling and "naming one's own reality"; revisionist interpretations or progress; intersectional theory; standpoint epistemology; essentialism vs. anti-essentialism; structural determinism; empathetic fallacy; and non-white cultural nationalism/separatism.

Ladson-Billings and Tate (1995) introduced CRT into education, highlighting how racism existed in educational systems disproportionately disadvantaging Black and other racialized students. Building off this work, Dumas and Ross (2016) further theorized Black critical theory (BlackCrit), which specifies that anti-Blackness is normalized and central to society and that Blackness is counter to neoliberal multiculturism. By utilizing BlackCrit to analyse desegregation and discipline in schools, Dumas and Ross (2016) showed how anti-Blackness results in the marginalization, disregard and distance for Black bodies in education. CRT themes have also been used in STEM education research to understand how racism exists in STEM teaching practices (Wallace \& Brand, 2012) and argue for acknowledgement and mitigation of whiteness in science education (Sammel, 2009). Specifically, BlackCrit has been used to articulate how STEM can be reframed as an anti-Black construct and that more scholars of STEM education need to consider not only equity broadly but specifically begin to address STEM's role in upholding and promoting anti-Blackness (Cedillo, 2018). Therefore, CRT provides a framework for academic critique and reflection upon how an institutionalized perception of race (including Blackness) can influence action and impact within one's operational context.

In the USA, more work has been done to understand how racism manifests in engineering education. Although not always explored through CRT, much of the literature highlights the inequities that exist for Black (Berhane et al., 2020; Blosser, 2020; McGee \& Martin, 2011), Indigenous (Page-Reeves et al., 2018) and other racialized students (McGee et al., 2017; Ong et al., 2020; Ro \& Kim, 2019) in engineering programmes. However, within the Canadian context, there is limited available literature providing critical reflections at the intersection of post-secondary STEM education, institutional operations and race-based considerations, particularly in the context of engineering education and Black inclusivity. This paper leverages a CRT framework to reflect on the practices and initiatives implemented to centre Blackness and address anti-Black racism within the engineering division of a large, research-centric university.

\section{K-12 Outreach}

In 2009, U of T FASE formally established the Engineering Student Outreach Office (ESOO). ESOO would be responsible for designing and delivering unique and innovative STEM programmes to connect the faculty and its students to youth from across the Greater Toronto Area (GTA), the province, the nation and worldwide. Programme offerings, delivered by employed undergraduate and graduate students, can take several forms including on-campus day camps, in-school workshops, in-school day camps, immersive multi-week on-campus experiences and leadership and mentorship programmes. All ESOO programming share similar goals of inspiring and cultivating K-12 students' interest and engagement in STEM, while also providing a combination of academic support, post-secondary preparedness and career-based knowledge to give participants insight into pursuing an engineering education and deriving personal meaning from the experience.

Unfortunately, the disparity and disproportionality of Black student experience within the GTA is well documented. Previous Toronto District School Board (TDSB) Census data has shown Black students 
underperforming academically and less likely to have a positive outlook on their school experience (particularly those from Caribbean- and Canadian-born parents) (Research and Information Services, 2015). Other TDSB data has shown Black students are up to three times more likely to get suspended compared to white students and can make up almost half (48\%) of the total number of expelled students within a given year (James \& Turner, 2017). Outreach programming is often leveraged by both community-based and academic institutions who wish to address student experience and learning gaps and stimulate interest in post-secondary education. The following section will focus on the development, successes and challenges of $\mathrm{U}$ of T FASE outreach programmes that target Black youth in grades 3-12 with the intention of supporting racial equity in STEM and post-secondary education.

\section{Programme/Initiative Development and Implementation}

In 2010, ESOO along with the U of T chapter of the National Society of Black Engineers (NSBE) students, created a programme for students in grades 3-8 called ENGage. This collaborative programme was intended to go beyond the typical goals of ESOO programming by addressing apparent racial disparities in STEM representation through creating an environment which leveraged early-age exposure to concepts, representation, role models and community. Providing a platform for Black representation and the diverse Black experience was considered key in addressing the imposter phenomenon and creating an inclusive environment (Gullatt \& Jan, 2002).

In 2019, the ESOO then developed a 4-week leadership programme for grade 10 and 11 students called Engineering Leadership to Inspire Further Education (EngLIFE). The goals outlined for this programme were built upon those for existing programming like ENGage (STEM exposure, platforming representation and experiences) and implemented unique programmatic elements to provide a holistic development opportunity for participating students. Some of those features included Black/POC instructor-facilitated design projects, curriculum-linked field trips, community-building field trips and connection to representatives of various university student services. The programme also offered students a TDSB high school credit in leadership and peer support through partnership with a local high school.

While the general feedback on this first iteration of the programme was positive, it was noted that there was some disparity in student interest and engagement, which could be traced back to how programme participants were selected. For this pilot, the students were hand-picked based on metrics determined by participating schools. Due to variation in selection metrics, some students were chosen based on aptitude and existing interest in STEM and others were chosen as individuals who would benefit from a non-traditional, holistic learning experience to gain a high school credit. EngLIFE instructors found it challenging to teach the students the content because of the vast differences in student knowledge on the topics, highlighting the need to distinguish "gap-spanning" programming from "enrichment" programming. The TDSB partnership was also found too restrictive for future iterations of the programme. Therefore, in 2020, the EngLIFE summer engineering leadership programme was re-envisioned to be a comprehensive on-residence 5-week experience under a new moniker: Blueprint.

For Blueprint, students completed a digital application and provided supplementary documents, including their most recent transcript, a reference from a science teacher or guidance counsellor and a statement of interest. Students were then shortlisted and interviewed before final selections, which were now done by the ESOO. By extending the length of the summer programme by a week, providing on-campus residence for the duration of the programme and planning for year-long engagement, Blueprint wanted to increase programme impact through increased touchpoints. However, due to the COVID-19 pandemic, the 2020 Blueprint programme was restructured as a 4-week remote learning experience, which included resources such as workshop materials, laptops and even Internet hotspots being sent to participants' homes as required. The programme successfully engaged 55 students, and programmatic exit surveys of participants showed that $91 \%$ of respondents rated the programme as very 
good or excellent with $88 \%$ stating that they would like to participate in other $\mathrm{U}$ of $\mathrm{T}$ programmes in the future. Therefore, the ESOO is committed to offering Blueprint for the summer of 2021 and beyond.

Two additional programmes were created to engage students within the community with no set academic or initial interest requirements: ENGage High School Saturdays and EngLIFE Outreach Workshops (EOWs). ENGage High School Saturdays is an on-campus mentorship programme for high school students interested in learning about STEM that runs over six Saturdays during the winter/spring season that facilitated either cohort or drop-in engagement of the programme. EOWs are workshops offered for schools, community groups, church groups and after-school programmes that serve primarily Black youth.

\section{Reflection: Cassandra Abraham}

Coordinating programming specifically in a predominantly white country is so much different from my previous experience running programmes in The Bahamas, where the students are also Black but are not racialized or marginalized. In my experience, I created outreach programmes for environmental learning. My goal was to introduce students to ecosystems and biodiversity while protecting them from wildlife. Today, my protection plan looks a lot different; for every Black boy or girl that walks on campus to experience our programmes, I am doing my best to protect students from discrimination. There is a constant innate feeling of concern about how students and staff would react to the mere presence of this group on campus. The reality is having a group of Black youth on campus is chartering new waters, and ensuring these students are treated as equals to their white counterparts cannot be downplayed. One bad experience for these students can lead to a negative perception of $U$ of $T$ and further push the narrative that this space is not for Black people.

Role modelling and representation are important elements in our programme, and mentorship roles are normally held by Black $U$ of $T$ engineering students, who share their experiences and express the feeling of non-belonging. For the university to move to a true place of inclusivity students like our programme, mentors' stories need to be told. Counter-storytelling themed under CRT (Delgado \& Stefancic, 1993) suggests that members from marginalized groups sharing their experiences challenge the status quo and highlight white privileges and systematic oppression.

It is always apparent at $\mathrm{U}$ of $\mathrm{T}$ when looking at the faces on the walls that Black people are an anomaly in this space. As a Black female, these programmes have become more than a job to me; they have become passion projects.

It is important for us to continue creating space for Black students to allow them to learn and express freely Black culture where it is not seen as "ghetto", in turn combating the imposter syndrome phenomenon among students and cultivating a feeling of welcome and belonging. The implementation of culturally relevant programming and not taking the "just paint it white" approach can be credited for our successes thus far (Ridgeway \& Yerrick, 2018).

It is important to note that, although these programmes are designed for Black students, being Black is just a part of their identities. Essentialism vs. anti-essentialism from CRT suggests that Black people do not all have the same needs, but needs are determined based on students' current position and family histories (Delgado \& Stefancic, 1993). Our students come from many different communities and cultures. We spent time in our programme to celebrate Blackness and took time and created space to celebrate the many layers of their identities while addressing their needs.

The continuation of this work is so important; parents and students continue to express the need and gratitude for the outreach programmes thus far. I am also grateful that the university not only provides a space at the table for Black students and staff but also allows us to create our own. 


\section{Race-Based Data Collection}

The Ontario Human Rights Code (OHRC) highlights race as 1 of 17 characteristics (known as "grounds") for which one cannot be discriminated against or harassed (Government of Ontario, Human Rights Code, R.S.O., 1990, c. H.19, 1990). However, the OHRC does permit the collection and analysis of data based on race (or other characteristics) once an organization believes that such barriers may exist, and under this pretext, data standard guidelines have been developed for the collection of race data within the province (Government of Ontario, 2018).

The collection of race-based data in post-secondary institutions such as the University of Toronto has been advocated for by various groups such as the Black Liberation Collective for several years (Reynolds, 2016). Data collection can occur at different stages of engagement with the university such as during the application process, upon admission/hiring and/or during experiential surveys. Prospective staff/faculty can voluntarily self-identify during the application process for applicant census purposes (not identifiable in the hiring process). Hired staff/faculty can self-identify within an employee equity census tied to their employee portal. This means the U of T FASE has access to information highlighting the percentage of applicants and the percentage of current employees who identify as Black (U of T Eng. Black Inclusion Steering Committee, 2019). However, the same could not be said for the student population. The Ontario Universities' Application Centre (OUAC), responsible for processing undergraduate applications to Ontario colleges/universities, does not provide an opportunity to collect race-based data as part of the "personal information" of an applicant (Ontario Universities Application Centre, 2020).

Universities with supplement application requirements could have a race-based self-identification question; however, to the knowledge of the author, Queen's University is the only Ontario university that asks for additional demographic data (including race) as an optional part of their application process (Queen's University, 2020). In institutions such as Ryerson University, current students can self-identify various demographics such as race through initiatives such as Diversity Self-ID (Ryerson University, 2019). The University of Toronto has recently launched an analogous initiative called the Student Equity Census, which allows students to self-identify various characteristics such as race (Adamopoulos, 2020).

\section{Programme/Initiative Development and Implementation}

To address gaps in race-based data (and other forms of demographic information) within the admission process, U of T FASE developed a pilot Engineering Applicant Census (EAC) to be integrated within the Applicant Portal for all students applying to engineering programmes at the $\mathrm{U}$ of $\mathrm{T}$ for the 2020-2021 admission cycle. The EAC consists of 10 questions that cover elements of identity including race, gender, sexual orientation, religion and (dis)ability. Applicants were notified that no one in the selection process is privy to the information nor does it impact the strength of their application. Applicants are also asked if they are willing to be contacted based on responses on the census to highlight potential supports and communities that may be of interest to them. This information is not tied to their student record (as demographic information for enrolled students will be collected through the institution-wide Student Equity Census).

The creation of the EAC was initially championed by the co-chair of the FASE Black Inclusion Steering Committee (BISC). BISC, through a report provided to the faculty, suggested several recommendations to address Black inclusivity, one of which was improve race-based data collection at points such as admission. The co-chair of FASE BISC approached interested colleagues within the EEDIAG to create a sub-committee responsible for driving the creation of the EAC. Over several months, a review of demographic questions leveraged in the National Census and existing $U$ of T surveys such as the Employment Equity Survey was done to develop question framing. In addition, consultation with various stakeholders such as the Multi-faith 
Centre, Recruitment, First Nations House and the Engineering Registrar office was done to address framing of questions, FAQ development and implementation logistics.

The motivation to collect race-based data in sectors such as education is to metricize relative differences in the impact of barriers to representation and success between various racialized groups particularly those who are disproportionately impacted by white colonialism in North America (George et al., 2019). For example, within the K-12 educational space, the TDSB implemented a Student and Parent Census where data is disaggregated by several demographic characteristics including race, allowing it to produce several ethno-racial sub-reports.

The TDSB Black Student Report highlighted differences in experiences between Black students (of different cultural backgrounds) compared to the average TDSB student through reported survey data. Black students, particularly those of Caribbean or Canadian heritage, were $13 \%$ less likely to enjoy school, were $15 \%$ less likely to view school as friendly, were $8-10 \%$ less likely to get along with other students and achieved up to $20 \%$ lower grades in grade 10, underscoring potential barriers to access and inclusion (Research and Information Services, 2015).

Within the post-secondary educational space, Black student leaders have advocated to have data on student presence, experience and performance disaggregated by race to support shared anecdotal stories of exclusion and/or discrimination within the Black and other racialized communities (Reynolds, 2016). In order to better understand potential barriers for inclusion and equity that students face, U of T FASE recently started collecting disaggregated data from surveys it would distribute to its students. However, such surveys focus on enrolled students and do not provide information on potential barriers that impact prospective Black students from accessing engineering programmes.

Data from surveys of incoming first-year students highlight an underrepresentation of individuals who self-identify as Black relative to the Black population of the Greater Toronto Area in which the U of T resides, with $3 \%$ of 2018 first-year welcome survey respondents self-identifying as Black compared to the $8.5 \%$ Black representation within the GTA population (U of T Eng. Black Inclusion Steering Committee, 2019). Tools such as the EAC would allow for an aggregate characterization of who is applying to engineering programmes, who is the faculty making offers to and who is accepting those offers. By doing this, U of T FASE could start to better understand where the barriers to access reside. Is the lack of representation due to a lack of adequate community engagement/recruitment which means less representation in the applicant pool? Is there a disproportionate filtering of applicants who self-identify as Black during selection process, implying potential systemic biases? Or is there a disproportionate number of applicants who self-identify as Black who are not accepting offers?

\section{Reflection: Mikhail Burke}

When I reflect on the process of implementing an initiative such as the Engineering Applicant Census, while there were several barriers to overcome, I feel it is important to highlight how such barriers were also overcome. Firstly, there was the presence of an "empowered champion", someone who feels very strongly about a particular issue within the operational framework of an institution and leverages the "squeaky wheel" modality, constantly pushing forward a proposed mandate to senior administrators. I would say that I was the empowered champion, constantly bringing up the need to collect more demographically disaggregated data within the faculty, particularly at admissions. It got to the point where I realized, for this to happen, I would have to drive the project myself, which I did.

I would also say being an administrator, who did both their undergraduate and doctorate studies within engineering, helped facilitate buy-in. In my experience, there is an underlying sentiment that engineers (or those trained as engineers or engineering researchers) can speak best to issues within their community and how to address them. While there can be both merit and issue with this, such a standpoint epistemological mindset is also a foundation of CRT which believes members of the Black community 
have a unique authority to speak on their own experiences and issues (Delgado \& Stefancic, 1993). An empowered champion like myself, who both self-identifies as Black and has an engineering positionality, can leverage such a mindset to drive change. Also, leveraging the engineering ethos is one that founded on being data-driven to solve problems and framing the EAC as a tool to fill a critical data gap was key in advocating for its adoption. While the value of data is by no means unique to engineering or higher education, I do wonder if the data-driven nature of the engineering faculty specifically played a role in a tool like the EAC being implemented there before any other faculty within the university.

One other important reflection point to share is that anti-Black racism is unique relative to "racism" as highlighted by its pervasiveness and impact throughout the entire world (Busey \& Coleman-King, 2020) including within non-white societies (Sautman, 1994). Care must be taken to ensure that means to address the unique and deep complexities of anti-Black racism are not exclusively confined to broad stroke initiatives to address EDI in general. Such broad initiatives, while perhaps well-meaning, may serve to mute the depth and uniqueness of the Black struggle and may reduce the efficacy of initiatives to address underlying causes of anti-Blackness.

Throughout my professional experience, I have seen and heard many within the Indigenous community express analogous sentiments which have led to advocacy for Indigenous initiatives being separated from other EDI initiatives. This discourse of the degree of essentialism between marginalized people or racialized people and how it may impact approaches to addressing consequences of racism is often discussed within critical race theory (Delgado \& Stefancic, 1993) particularly within various subcommunities who self-identify (or who are identified) as Black.

\section{Race-Centric Dialogue and Learning}

Hosting opportunities for faculty-wide dialogue on race and the racialized experience in engineering is another way $U$ of T FASE has tried to the address the perceived lack of awareness, understanding and acknowledgement of racialized experiences and racism in engineering education. These dialogues have been spearheaded by the EEDIAG. The EEDIAG is a group of faculty, staff and students all involved or interested in EDI work at FASE. The EEDIAG operates from a critical framework, acknowledging that power dynamics exist in engineering education and that, due to systemic and socio-political issues, different identities may have different experiences which may include exclusion and discrimination. While a few of the EEDIAG members are in EDI staff positions within U of T FASE, this is not true of most members who are doing EDI work in addition to their regular portfolios and/or course work based on the value they see in the work.

A goal of the EEDIAG is to provide spaces for dialogue about EDI issues because the group believes that raising consciousness and building community is a starting point for equity and inclusion. This practice was borrowed from Black feminist activists who have used community-based dialogue to build awareness and empower action (Davis, 1982; Hill Collins, 2009; Smith, 2000). The EEDIAG started hosting Open Conversations, semi-structured dialogues where members of the FASE community can engage in EDI discussions and share experiences, in November 2018. Since then, 1-2 Open Conversations were held each term. Every student, staff and faculty member, a community of approximately 7000 people, were emailed an invitation to each Open Conversation. Each session engaged between 50 and 60 people on average, with many repeat participants. These sessions have been attended predominantly by staff and graduate students. The registration data for the Open Conversations indicate that there has been notably less engagement from faculty and undergraduate students.

Typically, topics for these Open Conversations were related to EDI broadly, e.g. creating inclusive physical spaces, getting more involved in EDI actions and why spaces for specific identity groups are needed at universities. Sometimes race was discussed in these sessions but not always. Often race and 
racism were only discussed at an Open Conversation if brought up by a racialized participant sharing their experiences related to the broader topic.

\section{Programme/Initiative Development and Implementation}

In June 2020, the EEDIAG hosted a virtual Open Conversation on "Addressing Anti-Black Racism and Unpacking Active Allyship" as a response to the deaths of George Floyd and Regis Korchinski-Paquet and the continual increase in anti-Black violence in North America. The focus of the session was to (1) build awareness about recent events of anti-Black violence, (2) learn about resources available to learn more about racism in North America and (3) to learn about ways to support the Black community and take actions against anti-Black racism in their own departments, communities and homes. In the end, most of the session was spent discussing the particulars of the Black Lives Matter movement and why it was needed. At a post-session debrief, facilitators noted that participants also expressed discomfort in knowing how to approach talking about race and racism as well as uncertainty about how to be actively anti-racist. There was a sense that many participants wanted to engage in acts of "allyship" but were often unsure of what this meant or were worried about doing or saying the "wrong" thing.

In addition to Open Conversations, the EEDIAG coordinated EDI workshops through the Towards Inclusive Practices Series (TIPS) and hosted an Anti-Racism Content Club where members engaged with different types of content, i.e. articles, podcasts, video etc., and then reflect on what they learned at group discussions. At a TIPS session on the imposter phenomenon (IP), race and the racialized experience was included in the context that racialized people may experience IP differently than their white peers in post-secondary education (Cokley et al., 2017). For the Anti-Racism Content Club, new topics are picked monthly and discussions have centred on racialized experiences, the ways racism manifest at FASE and how members can work to be anti-racist. However, the group of people this initiative has engaged is smaller than compared to Open Conversations and TIPS, approximately five or six people per session with less than 30 people signing up to be a member as of fall 2020. Like the Open Conversations, invitations to attend TIPS workshops and to join the Anti-Racism Content Club were circulated by email to every member of the U of T FASE community. Facilitators of these initiatives have reported that participants are typically staff and students, similar to the Open Conversations.

\section{Reflection: Cori Hanson}

Institutional culture change for equity and inclusion in STEM is slow and challenging work especially when changes may misalign with professional identity (Brownell \& Tanner, 2012; Whittaker \& Montgomery, 2014).

The barrier to engagement in community discussions I hear about the most is time. Lack of time to learn about racialized experiences and racism in Canada, lack of time to attend events and meetings, lack of time to listen and lack of time to act. However, when considering what I have heard through a lens of critical race theory, I do not believe time is the real barrier. I believe the barrier to being anti-racist stems from a discomfort in talking about race in a society that has normalized racism. Instead of getting involved in difficult and possibly uncomfortable conversations, engineering education often ignores race and/or tries to quantify it, continually looking to prove racism and generalize experiences of racialized people. How many more times will predominantly white institutions ask Black faculty, staff and students to prove that they experience racism before people invest in change?

I have also been complicit in this discomfort. I wish it had not taken us over a year to host an Open Conversation that centred a discussion about race and anti-Black racism. My complicity as a white person made it easier for me to focus on equity, diversity and inclusion (EDI) broadly and not address anti-Black racism specifically. I have spent time increasing my own racial literacy, and 
will continue to do this work, but I wish I had put what I was learning into practice sooner instead of intellectualizing the problem.

Today, I better understand why the response to the inciting incident was harmful to the Black student community as well as why it was criticized by Black student groups. I wonder whether the response would have been different if there was more racial awareness and less discomfort in talking about how anti-Black racism manifests at U of T FASE. Race-centred dialogues are part of how I and U of T FASE can work to be more anti-racist; however, I believe we also need to create more mechanisms for accountability and systemic change so that these dialogues are not performative. Within the EEDIAG, we often remind ourselves to not focus on who is not showing up but who is. I am grateful for colleagues like Mikhail and Cassie, as well as many others, who continually show up to have difficult conversations, who call out inequities and are working towards real change.

\section{Barriers to Implementation}

Defined by the anecdotal experiences of the authors, commonly voiced barriers in the development, implementation and engagement of these initiatives were time, financial resources and lack of knowledge of the opportunity. Such hindrances to the adoption and impact of EDI and Black community-specific initiatives have been identified elsewhere (Brownell \& Tanner, 2012; Chalker-Scott \& Tinnemore, 2009). However, one can argue that these barriers are a consequence of a deeper cultural underpinning. When viewed through a CRT lens, barriers to implementation share roots within ideals of liberalism and neoliberalism such as academic objectivity, colour neutrality (or evasiveness), meritocracy and incremental rights-based changes. As CRT theorists have pointed out, these ideals can negatively impact work towards racial inclusivity and justice as they challenge the notion that racism is a deeply ingrained, systemic issue that influences currently observed outcomes and experiences within education and beyond (Delgado \& Stefancic, 1993). Within our context, we have characterized these barriers as meritocracy and engineering mindsets; whiteness and colour evasiveness; and perceived alignment with codes, policies and values.

\section{Meritocracy and Engineering Mindsets}

One potential underlying social force that creates barriers in implementing such initiatives is the social perception of meritocracy. The concept of a pure meritocracy is generally appealing: evaluate an individual based on their talents and achievements, not due to personal characteristics such as wealth or identity. The engineering ethos and mindset is one that typically associated with objectivity and an apolitical nature (Riley, 2008), resulting in many within the field to believe that participating within engineering and engineering education is itself a meritocratic process. Critical scholars had for decades argued against this perceived meritocracy, critiquing Western science and engineering (Franklin, 1985; Haraway, 1996; Harding, 1986; Seron et al., 2018; Slaton \& Pawley, 2018). These critiques have been seen in practice in research showing sexism (Blickenstaff, 2005; Hunt, 2016; Logel et al., 2007), homophobia (Cech \& Rothwell, 2018; Cech \& Waidzunas, 2011; Hughes, 2017) and anti-Black racism (Blosser, 2020; Fletcher et al., 2017; McGee \& Martin, 2011; Ong et al., 2020) in engineering. However, the attitude is that race is not relevant in engineering and the mindset of equality over equity persists. One reason is that EDI work is not explicitly reflected in the STEM educator professional identity (Brownell \& Tanner, 2012); therefore, being actively anti-racist may not be either. This is similar to the lack of racial literacy noted in the inciting incident and the response from the administration.

In the context of processes like university admissions, as identity-based characteristics such as race should not be leveraged in a purely meritocratic process, the logical conclusion often drawn is that there 
is no reason to collect race-based data. Even if one could argue that how universities contextualize and evaluate "talent" and "achievements" needs further scrutiny, is race-based data a fair feature to leverage for contextualization at an individual applicant level? Debate on this question is the crux of the discourse surrounding policies such as affirmative action and the fear of the backlash and perception of affirmative action may be a related barrier to collecting demographic data particularly at admissions. Considering the criticism that preeminent universities in the USA have faced with affirmative action policies (Students for Fair Admissions v. Harvard, 2017), it is apparent why analogous institutions in Canada would be weary of even the perception of leveraging racial (or other demographic data) in admissions.

However, regardless of one's position on leveraging demographic data to assess at the individual applicant level, Canadian institutions need to explain why demographic information is not collected and assessed only in aggregate to determine whether there are potential systemic barriers within application or selection processes. The University of Toronto already collects applicant demographic data (including ethnocultural identity) for staff and faculty positions for that very reason (University of Toronto, 2020). It is also interesting to note that OUAC already collects some demographic data for its applicants specifically gender and Indigeneity, meaning that all Ontario post-secondary institutions have access to some degree of demographic data even at the individual applicant level. The disconnect in already collecting some demographic data but no other forms, particularly race, highlights that there is likely something deeper acting as a barrier than just the perception of what is required for meritocratic action.

\section{Whiteness and Colour Evasiveness}

The next barrier to be discussed here is whiteness, an ideology and social construct that gives more power and privilege to white people compared to racialized people which manifests as behaviours, values and attitudes that maintain white supremacy (Frye, 1983; Kivel, 1996). Whiteness places white people in a place of structural advantage, positioning white culture as the normative culture, meaning it often goes unnamed and unquestioned (Frankenberg, 1993). A key characteristic of whiteness for this paper is that whiteness is often invisible to white people (Hooks, 1994). This invisibility perpetuates a lack of racial literacy and understanding of difference which is the basis for oppression (Hooks, 1994).

The invisibility of whiteness in engineering was likely a factor why many people had a challenging time prioritizing conversations and opportunities to learn about racism. Whiteness makes talking about race difficult and uncomfortable (Dua et al., 2005; Hooks, 1994). No one wants to be labelled an oppressor or a racist, especially white Canadians who were raised in a society that has historically invalidated race (Dua et al., 2005; Schick \& St. Denis, 2005). It can be uncomfortable acknowledging race because then one might also have to acknowledge how their race gives them privileges while oppressing others. That is true for all people, particularly those who experience more privileges than others under whiteness. In Canada, in engineering, at U of T FASE, it is simply easier to not talk about race than face this discomfort.

Recent polls taken after the resurgence of Black Lives Matter discourse in June 2020 have shown that $40 \%$ of Canadians view racism as an American issue and not a fundamental problem here in Canada (IPSOS, 2020). This invalidation of race or racism can be seen as a form of colour evasiveness (leveraging this term over the more commonly known colour "blindness" as to avoid ableist language) (Annamma et al., 2017). This colour evasiveness could also be an explanation as to why some demographic data is collected at admissions within Canadian post-secondary institutions but not others like race. Additionally, such colour evasiveness and racial avoidance has often led to ESOO fielding calls from parents of K-12 students who self-identify as non-Black, questioning why programmes like Blueprint exist "only for Black students", often resulting in cases where students who did not self-identify as Black enrolled into the programme. 


\section{Perceived Alignment with Codes, Policies and Values}

Another barrier to the implementation of these initiatives is perceptions of what is allowed by the Ontario Human Rights Code and/or the structure of existing university policies. In the case of the ESOO, there was an additional desire to have instructors from similar ethno-racial backgrounds as the students as representation within such roles has been shown to have positive impact on the learning and engagement experience (Gall et al., 2020). Unfortunately, there have been instances in which there has been a struggle to find representative student-staff. One reason for this could have been U of T FASE Human Resources perception on whether the Ontario Human Rights Code allowed for specific job descriptions to specify a preference that the applicant self-identify as Black as it was not allowed to be explicitly stated in Blueprint instructor job descriptions.

Similarly, many post-secondary institutions are perceived to have either held varying perceptions about the legality of collecting race-based information and/or have institutional policies that explicitly would prevent such information from being meaningfully leveraged (McDonald \& Ward, 2017). For example, if a donor wanted to provide funding to create an entrance scholarship for Black students to address systemic barriers, information on the self-identification of students would be needed. However, policies such as U of T Policy on Student Awards had prevented awards that had criterion such as specific racial identity. Therefore, there was no incentive to collect this data for award purposes as it could not be used (University of Toronto Governing Council, 1998) (note: U of T has recently created exceptions for awards specific for Black and Indigenous communities).

\section{Next Steps}

\section{K-12 Outreach}

To be a true agent of change and continue the fight against anti-Black racism, key areas for outreach have been identified. The Ontario "leaky pipeline" metaphor suggests that women are disproportionality unrepresented in the engineering field and only represent only $13 \%$ of professional engineers (Wells et al., 2018). It also highlights that the biggest leak occurs in high school where girls are not choosing STEM subjects. The implied reason for this is low confidence in their abilities in STEM subjects or no interest (LaForce et al., 2016). The pipeline does not include data of the number of Black students and even more specifically Black girls.

Intersectionality tells us that the experiences of Black girls are different from those of Black boys and white girls (Crenshaw, 1991). The continuation and addition to current programmes to include programming specifically for girls with spaces designated for Black girls would begin to help address the disparities in the pipeline. This intersectional lens is also important when accommodating and designing an inclusive learning experience for other intersecting identities such as LGBTQ2S + and (dis)abilities. As funding is a concern for most outreach programmes, leveraging current programmes that are not free and finding grants that focus on these specific areas continues to be a priority.

Community partnership will also propel these programmes and expand the reach of ESOO. Key partners have been identified, including Toronto Housing Community, TDSB Centre for Black Excellence and non-profits that continue to support Black students (e.g. Visions of Science). With continued support and space from the university, ESOO can continue to bridge the gap between Black students and post-secondary education in Ontario. 


\section{Race-Based Data Collection}

The pilot EAC has already garnered interest from other divisions within the University of Toronto who may want to collect similar information for the purpose of addressing similar barriers in their context. Many people value the EAC and the prospective outcomes as the foundation for advocacy in collecting this information provincially through integration of demographic (including race) questions in the central OUAC admission profile. The next steps are sharing the information on the implementation of the EAC to executive membership of the Ontario University Registrars' Association (OURA), highlighting the value such information has on barrier analysis with regard to post-secondary access and engagement of Black, racialized and other equity-deserving populations. OURA are key stakeholders in guiding OUAC operations. If OURA as a unified voice state the value of the collection of this information and their desire to have access to such information, a tool similar to the EAC could be embedded into the provincial application process, taking the barrier of institutions with varying degrees of resources each individually developing analogous tools.

\section{Race-Centric Dialogues and Learning}

The EEDIAG will continue to host faculty-wide opportunities for race-centric dialogue and learning. There are also ongoing discussions being held on other ways to incentivize and normalize EDI work at FASE. More researchers have started to engage in these discussions now that NSERC requires applicants to outline their EDI work and progress to receive funding. FASE has also started to explore embedding EDI requirements into teaching awards and tenure, although the latter will likely be a long and arduous process and whether this is even feasible is still unknown. Our current and previous deans have both invested in EDI at FASE through the creation of new staff roles (e.g. the Dean's Advisor on Black Inclusion and the Assistant Dean and Director for the new Diversity, Inclusion \& Professionalism Office) and by continuing to fund the EEDIAG and outreach initiatives. EDI change requires a top-down and bottom-up approach (Whittaker \& Montgomery, 2014). At FASE, we have started to implement both, we have support from the senior administration and we have started to see some momentum in grassroots individual interest. It will likely take time, resources and efforts of few to change the culture for many, but with persistence and dedication it is still possible.

\section{General Consideration}

While next steps in driving and building upon these key initiatives are important to highlight, we cannot forget that these programmes do not operate in a vacuum, but rather in an environment conducive to ignoring issues of anti-Blackness and other forms of racism. The only way to address racism is to be anti-racist, meaning that one must acknowledge and confront racism repeatedly in every aspect of our racist society (Kendi, 2019). Becoming anti-racist would be a major change for most engineering and post-secondary institutions including ours. However, unless these cultural and systemic issues are addressed, it seems unlikely that buy-in, engagement and involvement in EDI initiatives will change.

Collaborative projects within the USA such as the Transforming Engineering Culture to Advance Inclusion and Diversity (TECAID) project have developed a framework for engineering faculties within post-secondary institutions to more intentionally facilitate the integration of EDI values within various aspects of their operation (Matt, et al., 2018). Many aspects of this model could be leveraged within the Canadian context and further refined to address anti-racism. 


\section{Final Thoughts}

This paper highlighted initiatives that U of T FASE implemented and/or built upon in efforts to start to address anti-Black racism and racial inclusivity within its environment. Barriers to their implementation and success were often commonly shared and entrenched into the very culture and operation of Canadian engineering education. How does one incentivize the community to participate more? How does one get more resources to build programming? How does one educate and empower people to address inequity? There are no clear answers on how to overcome the barriers of colour evasiveness and perceived objectivity and meritocracy that embedded within the pillars of Canadiana and the engineering ethos. However, the experience within U of T FASE has shown that having a designated champion for specific initiatives, addressing discomfort in differentiating race, consistent advocacy to senior administration and, most importantly, the self-empowerment to resource time and effort to such work as key in the continual progress towards Black inclusivity and equity within Canadian STEM post-secondary education.

\section{Declarations}

Conflict of Interest Each author would like to acknowledge that they are currently an employee of the University of Toronto Faculty of Applied Science and Engineering, the institution whose initiatives are being discussed within the context of the manuscript.

\section{References}

Adamopoulos, T. (2020). U of T launches first-ever student diversity census to identify barriers to student success. University of Toronto News.

Annamma, S. A., Jackson, D. D., \& Morrison, D. (2017). Conceptualizing color-evasiveness: Using dis/ability critical race theory to expand a color-blind racial ideology in education and society. Race Ethnicity and Education, 20(2), 147-162.

Bell, D. A. (1992). Faces at the bottom of the well: The permanence of racism. New York: Basic Books.

Berhane, B., Secules, S., \& Onuma, F. (2020). Learning while Black: Identity formation and experience for five Black men who transferred into engineering undergraduate programs. Journal of Women and Minorities in Science and Engineering, 26(2), 93-124.

Blickenstaff, J. C. (2005). Women and science careers: Leaky pipeline or gender filter? Gender and Education, 17(4), 369-386.

Blosser, E. (2020). An examination of Black women's experiences in undergraduate engineering on a primarily white campus: Considering institutional strategies for change. Journal of Engineering Education, 109(1), $52-71$.

Brownell, S. E., \& Tanner, K. D. (2012). Barriers to faculty pedagogical change: Lack of training, time, incentives, and... tensions with professional identity? CBE Life Sciences Education, 11(4), 339-346.

Busey, C. L., \& Coleman-King, C. (2020, June). All around the world same song: Transnational anti-Black racism and new (and old) directions for critical race theory in educational research. Urban Education. https://doi.org/10.1177/ 0042085920927770

Cech, E. A., \& Rothwell, W. R. (2018). LGBTQ inequality in engineering education. Journal of Engineering Education, 107(4), 583-610.

Cech, E. A., \& Waidzunas, T. J. (2011). Navigating the heteronormativity of engineering: The experiences of lesbian, gay, and bisexual students. Engineering Studies, 3(1), 1-24.

Cedillo, S. (2018). Beyond inquiry: Towards the specificity of anti-Blackness studies in STEM education. Canadian Journal of Science, Mathematics and Technology Education, 18(3), 242-256.

Chalker-Scott, L., \& Tinnemore, R. (2009). Is community-based sustainability education sustainable? A general overview of organizational sustainability in outreach education. Journal of Cleaner Production, 17(12), 1132-1137.

Cokley, K., Smith, L., Bernard, D., Hurst, A., Jackson, S., Stone, S., Awosogba, O., Saucer, C., Bailey, M., \& Roberts, D. (2017). Impostor feelings as a moderator and mediator of the relationship between perceived discrimination and mental health among racial/ethnic minority college students. Journal of Counseling Psychology, 64(2), 141-154. 
Crenshaw, K. (1991). Mapping the margins: Intersectionality, identity politics, and violence against women of color. Stanford Law Review, 43(6), 1241-1299.

Crenshaw, K., Gotanda, N., Peller, G., \& Thomas, K., eds. (1995). Critical race theory: The key writings that formed the movement. New York: The New Press.

Davis, A. Y. (1982). Women, race \& class. London: Women's Press.

Delgado, R. (1995). Critical race theory: The cutting edge. Temple University Press.

Delgado, R., \& Stefancic, J. (1993). Critical race theory: An annotated bibliography. Virginia Law Review, 79(2), 461-516.

Delgado, R., Stefancic, J., \& Harris, A. (2017). Critical race theory: An introduction (Third edition.). New York University Press.

Dua, E., Razack, N., \& Warner, J. N. (2005). Race, racism, and empire: Reflections on Canada. Social Justice, 32(4), 1-10.

Dumas, M., \& Ross, K. (2016). Be real Black for me: Imagining BlackCrit in education. Urban Education, 51(4), 415-442.

Fletcher, T., Ross, M., Tolbert, D., Holly, J., Cardella, M., Godwin, A., \& de Boer, J. (2017). Ignored potential: A collaborative road map for increasing African American women in engineering. The National Society of Black Engineers, The Society of Women Engineers, and Women in Engineering ProActive Network.

Frankenberg, R. (1993). White women, race matters: The social construction of whiteness. Minneapolis: University of Minnesota Press.

Franklin, U. M. (1985). Will women change technology or will technology change women? Canadian Research Institute for the Advancement of Women, 9, 1-21.

Frye, M. (1983). On being white: Thinking toward a feminist understanding of race and race supremacy. In T. Burg (Ed.), Politics of reality: Essays in feminist theory. New York: Crossing Pres.

Gall, A. J., Vollbrecht, P. J., \& Tobias, T. (2020). Developing outreach events that impact underrepresented students: Are we doing it right? European Journal of Neuroscience, 52(6), 3499-3506.

George, R. C., Maier, R., \& Robson, K. (2019). Ignoring race: A comparative analysis of education policy in British Columbia and Ontario. Race Ethnicity and Education, 23(2), 159-179.

Government of Ontario. (1990). Human Rights Code, R.S.O. 1990, c. H.19.

Government of Ontario. (2018). Data standards for the identification and monitoring of systemic racism. Retrieved November 30, 2020, from https://www.ontario.ca/document/data-standards-identification-and-monitoring-systemic-racism

Gullatt, Y., \& Jan, W. (2002). How do pre-collegiate academic outreach programs impact college-going among underrepresented students? Pathways to College Network Clearinghouse.

Haraway, D. (1996). Simians, cyborgs, and women: The reinvention of nature. New York: Routledge.

Harding, S. G. (1986). The science question in feminism. Ithaca: Cornell University Press.

Harris, C. I. (1993). Whiteness as property. Harvard Law Review, 106(8), 1707-1791.

Hill Collins, P. (2009). Black feminist thought: Knowledge, consciousness, and the politics of empowerment (Second edition). New York: Routledge.

Hooks, B. (1994). Teaching to transgress: Education as a practice of freedom. New York: Routledge.

Hughes, B. E. (2017). "Managing by not managing": How gay engineering students manage sexual orientation identity. Journal of College Student Development, 58(3), 385-401.

Hunt, J. (2016). Why do women leave science and engineering? ILR Review, 69(1), 199-226.

IPSOS. (2020). Majority (60\%) see racism as a serious problem in Canada today, up 13 points since last year. Retrieved from https://www.ipsos.com/en-ca/majority-60-see-racism-serious-problem-canada-today-13-points-last-year

James, C., \& Turner, T. (2017). Towards race equity in education: The schooling of Black students in the Greater Toronto Area. Toronto: York University.

Kendi, I. X. (2019). How to be an antiracist. New York: One World.

Kivel, P. (1996). Uprooting racism: How white people can work for racial justice. Gabriola Island: New Society Press.

Ladson-Billings, G. \& Tate, W. F. (1995). Toward a critical race theory of education. Teachers College Record, 97(1), 47-68.

LaForce, M., Noble, E., King, H., Century, J., Blackwell, C., Holt, S., \& Loo, S. (2016). The eight essential elements of inclusive STEM high schools. International Journal of STEM Education, volume 3, article 21.

Logel, C., Walton, G. M., Spencer, S. J., Iserman, E. C., von Hippel, W., \& Bell, A. E. (2007). Interacting with sexist men triggers social identity threat among female engineers. Journal of Personality and Social Psychology, 96(6), 1089-1103.

Matt, D., Lawrey, A., Perry, T., Kokini, K., Litzler, E., Affolter, E., \& Glover, C. (2018). TECAID model: Leading engineering department culture change in diversity, equity, and inclusion.

McDonald, J., \& Ward, L. (2017). Why so many Canadian universities know so little about their own racial diversity. Canadian Broadcasting Corporation.

McGee, E. O., \& Martin, D. B. (2011). "You would not believe what I have to go through to prove my intellectual value!" Stereotype management among academically successful black mathematics and engineering students. American Educational Research Journal, 48(6), 1347-1389.

McGee, E. O., Thakore, B. K., \& LaBlance, S. S. (2017). The burden of being “model”: Racialized experiences of Asian STEM college students. Journal of Diversity in Higher Education, 10(3), 253-270.

Ong, M., Jaumot-Pascual, N., \& Ko, L. T. (2020). Research literature on women of color in undergraduate engineering education: A systematic thematic synthesis. Journal of Engineering Education, 109(3), 581-615. 
Ontario Universities Application Centre. (2020). 105 - Personal information. Retrieved from https://www.ouac.on.ca/ guide/105-personal-information/

Page-Reeves, J., Marin, A., Moffett, M., DeerInWater, K., \& Medin, D. (2018). Wayfinding as a concept for understanding success among Native Americans in STEM: "Learning how to map through life." Cultural Studies of Science Education, 14(1), 177-197.

Queen's University. (2020). University applicant equity census results. Retrieved from https://www.queensu.ca/ planningandbudget/equitycensus

Research \& Information Services. (2015). Census portraits - Ethno-racial series: Black student report. Toronto: Toronto District School Board. Retrieved from https://www.tdsb.on.ca/Portals/research/docs/reports/Portrait_Census201112_Black_FINAL_report.pdf

Reynolds, C. (2016). U of T to track race-based data of its students. Toronto: Toronto Star.

Riley, D. (2008). Engineering and social justice. San Rafael: Morgan \& Claypool.

Ridgeway, M., \& Yerrick, R. (2018). Whose banner are we waving? Exploring STEM partnerships for marginalized urban youth. Cultural Studies of Science Education, 13(1), 59-84.

Ro, H. K., \& Kim, S. (2019). College experiences and learning outcomes of women of color engineering students in the United States. International Journal of Gender, Science and Technology, 11(1), 55-82.

Ryerson University. (2019). 2019 Student diversity self-ID. Retrieved from https://www.ryerson.ca/diversity-self-id/stude nts/2019-student-diversity-self-id-report/

Sammel, A. (2009). Turning the focus from "Other" to science education: Exploring the invisibility of Whiteness. Cultural Studies of Science Education, 4(3), 649-656.

Sautman, B. (1994). Anti-Black racism in post-Mao China. The China Quarterly, 413-437.

Schick, C., \& St. Denis, V. (2005). Troubling national discourses in anti-racist curricular planning. Canadian Journal of Education, 28(3), 295-317.

Seron, C., Silbey, S., Cech, E., \& Rubineau, B. (2018). "I am not a feminist, but. . .": Hegemony of a meritocratic ideology and the limits of critique among women in engineering. Work and Occupations, 45(2), 131-167.

Slaton, A. E., \& Pawley, A. L. (2018). The power and politics of engineering education research design: Saving the 'small n.' Engineering Studies, 10(2-3), 133-157.

Smith, B. (Ed.). (2000). Home girls: A Black feminist anthology. New Brunswick: Rutgers University Press.

Students for Fair Admissions v. Harvard (2017).

U of T Eng. Black Inclusion Steering Committee. (2019). Striving towards Black inclusivity. Retrieved from https://www. engineering.utoronto.ca/files/2020/02/Striving-Toward-Black-Inclusivity-Report-to-U-of-T-FASE.pdf

University of Toronto. (2020). Report on Employment Equity 2020. Retrieved from https://hrandequity.utoronto.ca/wpcontent/uploads/2021/06/U-of-T-Report-on-Employment-Equity-2020.pdf

University of Toronto Governing Council. (1998). Policy on student awards established in the University of Toronto. Retrieved from https://governingcouncil.utoronto.ca/sites/default/files/import-files/p04214832.pdf

Wallace, T., \& Brand, B. R. (2012). Using critical race theory to analyze science teachers culturally responsive practices. Cultural Studies of Science Education, 7(2), 341-374.

Wells, M. A., Williams, M., Corrigan, E., \& Davidson, V. (2018). Closing the gender gap in engineering and physics: The role of high school physics. University of Guelph, 2.

Whittaker, J. A., \& Montgomery, B. L. (2014). Cultivating institutional transformation and sustainable STEM diversity in higher education through integrative faculty development. Innovative Higher Education, 39(4), 263-275.

Publisher's Note Springer Nature remains neutral with regard to jurisdictional claims in published maps and institutional affiliations. 